\title{
A educação musical como instrumento psicopedagógico no atendimento a crianças com transtorno do espectro do Autismo
}

The musical education as psychopegagogic instrument of attendance to children with Autism Spectrum Disorder

Daniele Pincolini Pendeza ${ }^{1}$

Tânia Maria Filiú de Souza² 


\section{Resumo}

Este artigo abordará a utilização da música e seus elementos como suporte psicopedagógico no atendimento a crianças com diagnóstico do Transtorno do Espectro do Autismo, que são recebidas em escolas regulares e/ou em escolas de música da cidade de Santa Maria - RS. A pesquisa é qualitativa e de cunho bibliográfico, apresentando uma proposta de educação musical infantil estruturada em momentos pré-definidos e que valorizam as canções da infância. Para a constatação e eficiência, será utilizado como instrumento de coleta de dados o questionário, sendo aplicado a vinte responsáveis e professores de tais crianças. Os sujeitos do estudo estão compreendidos entre as idades de zero a doze anos, totalizando quatro crianças que receberam atendimento por no mínimo três meses.

Palavras-Chave: autismo, educação musical. psicopedagogia.

\section{Abstract}

This article will cover the use of music and its elements as psychopedagogic support in attendance of children with diagnostic of Autism Spectrum Disorder that frequent regular schools and/ or music schools in Santa Maria - RS. The research is qualitative and has bibliographic nature, presenting a childish musical education proposal structured on predefined moments with emphasis in childhood songs. A questionnaire was used as data acquisition mechanism to verify its efficiency, applied to twenty managers and teachers of those children. The subjects of this study are between the ages of zero to twelve years, and four of them received treatment for at least three months.

Keywords: autism, musical education, psychopedagogy. 


\section{Introdução}

O presente artigo propõe-se a tratar da educação musical como um instrumento psicopedagógico, seja em sala de recursos ou dentro da sala de aula regular, a fim de facilitar a educação e a aprendizagem de crianças com diagnóstico de Transtorno do Espectro do Autismo (TEA), um Transtorno Invasivo do Desenvolvimento (TID) que se apresenta em diversos níveis de severidade. A pesquisa é apresentada de forma qualitativa e de cunho bibliográfico, utilizando-se de questionário aplicado a pais, cuidadores e professores, da cidade de Santa Maria - RS, para a verificação dos dados pesquisados.

Tal trabalho foi impulsionado pela prática da autora como educadora musical. A mesma realiza atendimentos individuais, em uma sala de recursos de escola de ensino regular, onde recebe crianças com diagnóstico do TEA. Os alunos frequentam classes heterogêneas, não exclusivas para deficientes. Através de tal prática, surgiu o interesse em se verificar a efetividade de tais atendimentos através do olhar psicopedagógico, não só dentro da sala de recursos, mas também no que é trabalhado em sala de aula.

Através da recente implementação das leis de música e da inclusão do autista nas escolas, podemos verificar uma falta de preparo tanto dos professores e equipe escolar quanto das questões que envolvem a estrutura física destes ambientes. Como a música dá a possibilidade de se trabalhar com poucos materiais (no caso da música corporal, utiliza-se apenas o próprio corpo), é um ótimo meio para cumprir com a legislação e, por conta de seu caráter lúdico e afetivo, tornar-se um material em potencial para o trabalho com crianças com o diagnóstico do TEA.

A música por si só já é inclusiva, considerando que a grande maioria da população é afetada ativa ou passivamente por sons musicais diversos durante o dia a dia. Pelo fato de possuir caráter não só educativo, mas também terapêutico e de diversão, atinge diversos âmbitos do mesmo ser, proporcionando uma interação global do sujeito com os sons.

\section{A educação musical e a psicopedagogia}

A educação musical passou a integrar o currículo da educação básica desde a aplicação da Lei nำ11.769, de 18 de agosto de 2008, vindo a ser conteúdo obrigatório do componente curricular. Além desta, também temos a Lei n‥ 12.764, que institui a "Política Nacional de Proteção dos Direitos da Pessoa com Transtorno do Espectro Autista". Sancionada em dezembro de 2012, prevê que as pessoas com autismo sejam consideradas oficialmente pessoas com deficiência, tendo direito de usufruir das políticas de inclusão vigentes no país.

A partir de tais mudanças constitucionais, podemos verificar uma profunda e corrente alteração no ambiente escolar, o que exige ainda mais do papel do psicopedagogo, considerando que muitas destas medidas são aplicadas antes mesmo de se haver um preparo eficiente do corpo docente e da sociedade. Para tanto, o psicopedagogo, através da música e seus elementos, poderá trabalhar com as crianças 
com TEA e, assim, facilitar sua inserção em sala de aula, bem como ajudar os outros profissionais da educação na verdadeira inclusão. A música faz parte do cotidiano das crianças (sujeitos de zero a doze anos, segundo o Estatuto da Criança e do Adolescente) desde o período gestacional, sendo que, "ao nascer, os bebês já são sensíveis a diversas propriedades dos sons, tais como altura e intensidade" (ILARI, 2006, p. 275). As crianças recebem influência direta dos gostos de seus pais e familiares, mas é da escola o papel de direcionar para a aprendizagem de conteúdos propriamente musicais e trabalhar, através da musicalização, para a ampliação do gosto, bem como do desenvolvimento das capacidades cognitivas. Segundo Bertoluchi (2011), "a musicalização (...) ainda auxilia no desenvolvimento e aperfeiçoamento da socialização, alfabetização, capacidade inventiva, expressividade, coordenação motora e motricidade fina, percepção sonora, percepção espacial, raciocínio lógico e matemático e estética". O estudo e a prática musical, seja individual ou em conjunto, favorecem a abertura de canais de comunicação e, através do profissional da psicopedagogia, que traz a característica de ser um mediador aluno-escola-família (BONORA, 2010, p. 02), esses resultados podem ser otimizados.

Considerando a formação do psicopedagogo e seus conhecimentos acerca das deficiências, principalmente do TEA, o incremento do estudo da música pode ser direcionado para as necessidades específicas do aluno e, assim, usada a fim de potencializar a aprendizagem de outras disciplinas e aprimorar fatores relativos à cognição da criança.

A música, através de sua prática direcionada e focada no desenvolvimento global do sujeito, poderá "desenvolver na criança uma atitude positiva para este tipo de manifestação artística, capacitando-a para expressar os seus sentimentos de beleza e captar outros sentimentos, inerentes a toda a criação artística" (BERTOLUCHI, 2011, p. 02). Isso nos mostra que o potencial da educação musical vai além do desenvolvimento de conteúdos musicais e da prática instrumental, podendo afetar o indivíduo cognitiva e sensorialmente, ajudando na construção e formação do eu de forma integrada e lúdica.

Um dos problemas encontrados nas instituições de ensino, quando se fala em educação musical, é a falta de conhecimento acerca dos benefícios que a música pode proporcionar além da aprendizagem de seus conteúdos específicos. Tal desvalorização também é encontrada junto ao profissional da psicopedagogia, que ainda não tem sua importância reconhecida frente às esferas públicas do país, muitas vezes restando como supérfluo e, até mesmo, totalmente desconhecido. Além disso, mesmo após a aplicação de leis que implementam a música aos currículos escolares e a necessidade de profissionais que atuem com crianças que apresentem necessidades especiais, são poucos os locais que realmente trabalham de forma integrada e voltada para as necessidades reais de seus alunos.

Por conta das dificuldades citadas, além do fato de existirem poucos sujeitos habilitados e que estejam exercendo seu trabalho nas escolas, não se encontra professores de música e psicopedagogos atuando em conjunto no ambiente institucional. Tal fato acarreta ao psicopedagogo a tarefa de pesquisar e aplicar por si só os métodos e instrumentos musicais que possam lhe ser úteis. 
Na presente pesquisa, que envolverá a prática musical e psicopedagógica de forma simultânea, a autora utilizou-se do livro Bebê - Música e Movimento: orientação para musicalização infantil, de Josette S. M. Feres, para estruturar os atendimentos que aconteceram em salas de recurso de escolas de ensino formal e em uma escola de música da rede particular. O livro traz indicações de como organizar uma aula de musicalização para crianças, mas não constitui um método. Segundo Feres (1998), a aula de música tem por principal objetivo desenvolver o prazer de ouvir e fazer música na criança, além de valorizar a criatividade e o repertório folclórico, estreitar os laços afetivos, estimular a fala, ensinar o reconhecimento de regras e limites, desenvolver a musicalidade, percepção auditiva e psicomotricidade.

O material de Feres (1998) apresenta momentos fixos, dentro dos quais se modifica o repertório. Esses momentos compreendem: brinquedo livre, que é um espaço antes da aula para a criança ir se ambientando à escola; canto de entrada, que indica o início das atividades; hora do canto, momento de exploração vocal com vocalizações e o canto propriamente dito. Ainda, parlendas, rimas e brincadeiras musicais; marchas, danças e cirandas; conjunto de percussão; relaxamento, espaço em que as crianças têm um momento de apreciação musical, e, por fim, o canto de despedida.

A partir de tais propostas, algumas adaptações foram realizadas às especificidades dos alunos que compareciam aos atendimentos realizados pela autora, sendo que a primeira delas se refere ao fato de as aulas serem individuais, para valorizar a interação 1x1, e a professora poder atentar às dificuldades de manulação (escolha da mão que irá articular o instrumento) e dedilhado. Um ponto de divergência foi o fato de a criança frequentar a aula sem o acompanhamento de um responsável, a fim de que ela pudesse ter mais autonomia, desde o primeiro contato com a música, dentro do atendimento.

A sala de aula foi pensada e estruturada para a potencialização das ações ali realizadas. No chão, foi colocado um tatame para maior conforto ao sentar-se e também a fim de diminuir impactos causados por birras e acessos de raiva. Existem dois armários, um aberto, para guardar materiais pessoais, e um fechado com gavetas, para guardar os instrumentos e outros itens que não estiverem sendo utilizados em aula. Não há a presença de enfeites e móbiles para evitar a dispersão da atenção da criança e fazê-la concentrar-se nas atividades que estiverem sendo realizadas. As tomadas são todas fechadas com material apropriado, que só é retirado pela professora quando há a necessidade de objetos que utilizem energia elétrica. Para facilitar a visualização dos momentos, os instrumentos e materiais das atividades são dispostos horizontalmente, da esquerda para a direita, e em cestinhas, assim a criança pode observar o que será realizado e se preparar de antemão para o que for esperado dela. Desde o primeiro atendimento, que tem frequência semanal e duração de cinquenta minutos, propõe-se que a criança vá até as cestinhas e se posicione para a atividade. Ao final, logo após a utilização dos materiais, a criança deve guardá-los em local indicado, para que, além dos conteúdos musicais, seja estimulada a organização.

A autora optou pela utilização do violão para o acompanhamento das canções. O instrumento foi escolhido pela facilidade de locomoção que dá ao executante, podendo ser utilizado enquanto este se encontra sentado ou em pé, com o auxilio de uma correia. A criança tem contato com o violão da professora sempre que solicitado 
e também com tambores, chocalhos, guitarra elétrica, bateria, flauta doce e teclados. Além dos instrumentos, também são encontrados materiais para a realização de histórias sonorizadas, como ursos de pelúcia, fantoches, brinquedos diversos, materiais reutilizados, desenhos impressos e plastificados na forma de cartões, fichas de EVA e um travesseiro para o momento do relaxamento.

Em alguns momentos de apreciação, ou de atividades que requeiram maior interação da professora, são utilizados computadores e aparelhos de som, bem como o canto a cappella (sem acompanhamento). Tais itens dão a possibilidade de uma maior proximidade com a criança. Também há a utilização de recursos como animações gráficas das canções e das histórias, áudio-visuais de grupos musicais e a própria execução de peças em conjunto, que seriam inviáveis dentro da sala de aula, como apresentações de corais, orquestras, bandas e grupos de câmara.

Como algumas crianças com autismo mostram um grande grau de atividade motora e têm dificuldade em manter a atenção, para evitar correrias e dispersões durante a aula, é estipulado que permaneça sentada durante as atividades que assim a requerem. Se a criança desrespeita essa regra, a música para e só recomeça quando ela retorna ao local especificado. Porém, existem algumas exceções, caso a criança se mostre participativa, dance, movimente-se com os instrumentos, então lhe é permitida a locomoção fora dos momentos estipulados para tal prática. O que rege esta regra são o foco e a participação na atividade proposta.

Os atendimentos visam a trabalhar a música e seus elementos de forma ativa, através de experimentação corporal e instrumental, não utilizando a música apenas como instrumento de comando ou pano de fundo para outras atividades. Segundo o Referencial Curricular Nacional para a Educação Infantil,

constata-se uma defasagem entre o trabalho realizado na área de Música e nas demais áreas do conhecimento, evidenciada pela realização de atividades de reprodução e imitação em detrimento de atividades voltadas à criação e à elaboração musical. Nesses contextos, a música é tratada como se fosse um produto pronto, que se aprende a reproduzir, e não uma linguagem cujo conhecimento se constrói (RCNEI, 1998, p. 47).

Além disso, são privilegiadas as canções do repertório infantil, canções folclóricas e populares brasileiras, músicas de outros povos, gêneros e ritmos variados e proposições dos responsáveis da criança, que envolvem músicas apreciadas em casa (que agradem ao gosto da criança) e na escola (que estejam sendo utilizadas em alguma atividade). As atividades são entremeadas por explicações a cerca do repertório e dos elementos musicais encontrados nele, a fim de se trabalhar primeiramente a música como um todo e só então apresentar seus elementos de forma separada.

O gosto da criança é respeitado, havendo alterações no repertório quando este não se mostra adequado e não incita prazer durante as atividades. Tal ponto é atentado no cotidiano e investigado junto aos responsáveis desde o primeiro encontro, pois, segundo pesquisas realizadas por diversos autores, a criança já desenvolve seu gosto e entendimento estético desde os primeiros anos de vida. 
O uso de música no dia a dia dos bebês ultrapassa as barreiras temporais e culturais. Já no primeiro ano de vida, os bebês exibem preferência por cantores e maneiras de cantar, demonstram indícios de percepção de emoção em música, além de possuir capacidades cognitivas notáveis de armazenamento de música conhecida na memória de longo prazo (ILARI, 2006, p. 288-9).

Observamos que, sem uma prática musical devidamente direcionada, a aprendizagem se dá de forma custosa e até mesmo desestimulante, fazendo-se necessária a presença de um profissional para agir como mediador entre os conteúdos e a criança. Sobre esta mediação, Vigostky (1998) nos traz o conceito da Zona de Desenvolvimento Proximal (ZDP), que se trata da distância entre o nível de desenvolvimento real (a capacidade de resolver problemas sem ajuda) e o nível de desenvolvimento potencial (a resolução de problemas com ajuda de um tutor seja ele um professor ou colega). Ou seja, a ZDP é o conhecimento em potencial da criança, que pode ser desenvolvido com a ajuda e orientação de alguém que já tenha ultrapassado a etapa a ser problematizada.

Podemos observar a importância da mediação do professor para facilitar a superação de dificuldades encontradas no processo de aprendizagem da primeira infância quando atentamos ao ato de manipular os instrumentos musicais, sendo o próprio corpo compreendido nesse grupo, pois

\begin{abstract}
a criança em idade escolar não costuma escutar o som da música que ela mesma produz, grita quando canta e bate nos instrumentos, ao invés de tocá-los, a menos que tenha sido especialmente sensibilizada ou treinada para proceder de forma diferente, ou caso tenha ao seu redor modelos capazes de induzir comportamentos mais refinados que os correspondentes à sua idade. Energia física e afetividade estão intimamente entrelaçadas nela; gosta de explorar o mundo sonoro e manipula os sons espontaneamente (GAINZA, 1988, p. 23).
\end{abstract}

Outro fator mediador no atendimento psicopedagógico é a própria educação musical, que age como intermediária entre o professor e o aluno, ampliando o potencial da relação intersocial, além de trabalhar no âmbito intrasocial, mediando a criança com seus próprios sentimentos. De acordo com Gainza (1988), corresponde à educação musical "instrumentalizar com eficácia os processos espontâneos e naturais necessários para que a relação homem-música se estabeleça de uma maneira direta e efetiva".

\title{
2. A criança com autismo
}

O termo autismo foi utilizado pela primeira vez pelo suíço Eugene Bleurer, em 1911, a fim de definir um sintoma da esquizofrenia como uma fuga da realidade. Já em 1943, foi empregado pelo austríaco Leo Kanner, quando este observou crianças com prejuízos na comunicação, comportamento e interação social, caracterizando esta condição em seu artigo Autistic disturbance of affective contact.

No mesmo ano, o também austríaco Hans Asperger utilizou o termo autismo em sua tese de doutorado como sendo uma "psicopatia autista da infância". O traba- 
Iho de Asperger só veio à tona após a tradução para o inglês, de Lorna Wing, nos anos 1970, o que tornou conhecida uma forma de autismo de alto desempenho, chamada de Síndrome de Asperger.

Wing (1981) também é conhecida pela sua pesquisa sobre o autismo em um olhar psicanalítico, tendo criado a Tríade de Wing, que postula as dificuldades que a criança autista tem nas áreas de imaginação, socialização e de comunicação. Além disso, a psiquiatra inglesa observou que a incidência do autismo é maior em meninos, sendo que, quando manifesto em meninas, o grau de severidade é mais acentuado.

Em 1978, o psiquiatra inglês Michael Rutter definiu o autismo através de quatro critérios: "atraso e desvio sociais não só como função de retardo mental; problemas de comunicação, novamente, não só em função de retardo mental associado; comportamentos incomuns, tais como movimentos estereotipados e maneirismos; e início antes dos trinta meses de idade" (MAROT, s/d).

Segundo as informações do Código Internacional de Doenças e Problemas Relacionados com a Saúde, em sua décima edição (CID-10), o autismo infantil é um

transtorno global do desenvolvimento caracterizado por a) um desenvolvimento anormal ou alterado, manifestado antes da idade de três anos, e b) apresentando uma perturbação característica do funcionamento em cada um dos três domínios seguintes: interações sociais, comunicação, comportamento focalizado e repetitivo. Além disso, o transtorno se acompanha comumente de numerosas outras manifestações inespecíficas, por exemplo fobias, perturbações de sono ou da alimentação, crises de birra ou agressividade (auto-agressividade) (CID-10, F84.0).

Outra fonte que nos dá uma caracterização do quadro que compõe o autismo é o Manual Diagnóstico e Estatístico de Transtornos Mentais (DSM-IV-TR). Em sua quarta edição, encontramos o autismo como um Transtorno Invasivo do Desenvolvimento (TID), com grande déficit na interação social e comunicação, atividades e interesses restritos e ampla variação no grau de severidade. Pode haver dificuldade em demonstrar e perceber emoções alheias, dificuldade em desenvolver relacionamentos, ausência de contato visual, não demonstração de interesses, atraso ou falta total de comunicação verbal, presença de ecolalias e estereotipias, ausência da capacidade de abstração, dificuldade em aceitar mudanças de rotina, interesse insistente por partes de objetos ou do corpo.

O DSM-IV-TR também traz informações acerca de comorbidades, como retardo mental, hiperatividade, desatenção, impulsividade, agressividade, hipersensibilidade ao toque e aos sons, distúrbios alimentares e do sono, anormalidades do humor. Além de tais caracterizações, ainda observamos que o grau de severidade pode mudar ao longo dos anos, sendo que,

em bebês, pode-se perceber a ausência de aninhamento, uma indiferença ou aversão à afeição ou contato físico, falta de contato visual direto, de respostas faciais ou de sorrisos sociais e uma ausência de resposta à voz dos pais. Como resultado, estes podem preocupar-se, inicialmente, com a possibilidade de a criança ser surda. As crianças pequenas com o transtorno podem tratar os adultos como se pudessem ser trocados por outros ou podem agarrar-se mecanicamente a uma pessoa específica. Ao longo do desenvolvimento, a criança pode deixar-se envolver passivamente em interações sociais e até mesmo interessar-se pela interação social. Entretanto, mesmo nesses casos, ela tende a tratar as outras pessoas de 
maneira incomum (por ex., esperar que as outras pessoas respondam a perguntas ritualizadas de maneira específica, ter pouco senso das limitações alheias e invasividade imprópria na interação social) (DSM-IV-TR, 2002, p. 135).

Atualmente, os estudos apontam que a incidência do autismo típico é de dois a cinco sujeitos para cada dez mil. Isso nos mostra que devemos dar mais atenção a estas crianças, pois, com sua inserção no ensino formal, eles ocuparão diversos espaços que ainda não estão preparados para a sua chegada, necessitando-se de uma maior infra-estrutura e de profissionais capacitados. Além disso, a escola é socializadora e de grande potencial para a aprendizagem e desenvolvimento global da criança, é um ambiente onde se devem desenvolver não apenas a inclusão da criança com autismo, mas também a conscientização dos demais estudantes e corpo de professores e funcionários.

A criança, e principalmente a criança com necessidades especiais, carece ser valorizada como ser humano, ao mesmo tempo em que tem o direito de receber uma educação de qualidade, a fim de lhe proporcionar um futuro digno. Para tanto,

é importante destacar que quanto mais cedo se inicia a intervenção, melhores resultados são alcançados num período menor de tempo. Portanto, uma intervenção eficaz logo no começo do processo de escolarização contribuiria para o melhor desenvolvimento futuro desses sujeitos, permitindo-lhes maior qualidade de vida, aprendizagens e acesso para conviverem permanentemente em sociedade (BERTAZZO; MOSCHINI, 2012, p. 2).

A valorização do indivíduo vem atrelada à valorização da infância, pois a criança com autismo é antes de tudo criança e deve viver a sua fase de desenvolvimento de forma plena, tendo suas características pessoais respeitadas. Ao encontro disso, temos a educação musical focada no repertório infantil e trazendo a possibilidade de exploração instrumental, vocal e corporal. Podendo desenvolver não apenas aptidões musicais, mas também faculdades para a convivência em grupo, a relação consigo mesmo e aptidões a serem utilizadas em outras profissões.

Segundo Louro (2004/2006), "percebemos por parte de muitos, mesmo de educadores musicais, a crença de que fazer música é somente tocar um instrumento musical", o que se torna um fator limitador e, muitas vezes, dá margem a preconceitos com relação à amplitude que a educação musical pretende abarcar, desenvolvendo diversos conteúdos, repertórios e possibilitando experimentações como as já citadas. Louro também nos traz que devemos nos desligar do ideal romântico de que a música é apenas o desenvolvimento técnico de um instrumento até sua excelência, pois a música vai além de tal desenvolvimento, vai além da técnica e não necessita ser praticada apenas com o intuito de profissionalização.

A criança com autismo pode e deve se beneficiar de todos os conteúdos e possibilidades que a música abarca e potencializa, vivendo sua infância de forma lúdica e criativa, recebendo as mesmas oportunidades e chances que qualquer outro indivíduo. $E$, quanto mais o aprendiz tiver oportunidade de ressignificar o mundo por meio da especificidade da linguagem da arte, mais poder de percepção sensível, memória significativa e imaginação criadora ele terá para formar consciência de si mesmo e do mundo (MARTINS, PICOSQUE e GUERRA, 1998 apud SOARES, 2002, p. 212). 
De todos os benefícios e potencialidades que a educação musical proporciona, observamos que sua aplicação e averiguação não está dissociada de outras áreas do conhecimento, devendo ser tratada de forma multidisciplinar para melhor obtenção de resultados, pois devemos recordar que,

\begin{abstract}
quando falamos em desenvolvimento cognitivo-musical, estamos falando não apenas no desenvolvimento do cérebro ou de habilidades que fazem parte dos testes tradicionais de inteligência, mas do desenvolvimento da mente como um todo, já que o desenvolvimento humano não deve estar dissociado de outros contextos como, por exemplo, o contexto social. O estudo do desenvolvimento cognitivomusical é muito complexo e deve, necessariamente, incluir aspectos psicológicos, sociais, culturais, emocionais, motores e físicos, entre outros (ILARI, 2006, p. 294-5).
\end{abstract}

A música, como sendo um meio de comunicação não-verbal, é uma linguagem que facilita a expressão de sentimentos e dá uma nova alternativa de comunicação, possibilitando uma maior descoberta de quem a pratica e interação com seus pares. Tais fatores são de grande importância para a criança com autismo, pois isto a conecta com o ambiente e cria um meio que possibilita a vazão de suas pulsões.

Ao trabalhar a percepção auditivo-visual através dos sons, e a psicomotricidade fina através da experimentação instrumental, a criança com autismo tem a oportunidade de experienciar uma grande gama de estímulos sensoriais que lhe proporcionarão um maior desenvolvimento de suas aptidões, bem como a gênese de novas capacidades. A aproximação física e, até mesmo, a permissão ao toque são facilitadas com o intermédio dos instrumentos musicais, bem como a manutenção da atenção, já que o foco está no próprio executante, que se envolve e é envolvido pela prática.

O corpo deve ser tratado como um instrumento musical e os instrumentos como prolongamentos do corpo, fazendo com que o sujeito que executa música traga à tona os seus sentimentos e os seus sentidos rítmicos, melódicos e harmônicos. Sendo que

toda ação expressiva é, por um lado, efeito, mostra ou representação de algo e, por outro, causa ou origem de um produto expressivo. [...] Toda conduta expressiva é projetiva e, como tal, tem a qualidade de refletir aspectos da personalidade. Alguém que faz alguma coisa está se expressando, qualquer que seja o grau, caráter e qualidade de sua atividade ou do produto desta. [...] Expressar-se é, pois, demonstrar tanto as deficiências como as capacidades (GAINZA, 1988, p. 29).

Esse envolvimento do corpo facilita a aprendizagem e mobiliza todo o ser, por conseguinte tornando-se mais que um "objeto sonoro, concreto, específico e autônomo", mas também "aquilo que simboliza, representa ou evoca" (GAINZA, 1988, p. 34). Tal envolvimento corporal pode ser de grande valia quando recordamos das dificuldades da criança autista em focar a atenção e em manter contato visual, visto que a música age como integradora dos sentidos.

A música, como o ser humano, é dinâmica e não se restringe a moldes. Brito (2003) apresenta a produção de outros povos e os diferentes gêneros e ritmos que se pode encontrar onde são vistas linhas melódicas que apresentem mobilidade e margem para improvisos, bem como as produções ortodoxas que se utilizam apenas de instrumentos e sons convencionais. A partir disso, podemos perceber que a música é 
tão heterogênea quanto são seus produtores e apreciadores.

A valorização da criança para a construção do seu ser e de sua musicalidade perpassa a ludicidade, o jogo e o divertir-se, pois

a criança é um ser "brincante" e , brincando, faz música, pois assim se relaciona com o mundo que descobre a cada dia. Fazendo música, ela, metaforicamente, "transforma-se em sons", num permanente exercício: receptiva e curiosa, a criança pesquisa materiais sonoros, "descobre instrumentos", inventa e imita motivos melódicos e rítmicos e ouve com prazer a música de todos os povos (BRITO, 2003, p. 35).

A criança, o som e a música unem-se como um só e ultrapassam as barreiras da educação musical, da interação intra e intersocial e da terapia, construindo, assim, um enfoque multi e transdisciplinar. Quando a criança explora e experiencia a música, não há certo ou errado, há crescimento. $O$ atendimento psicopedagógico a crianças com autismo através da educação musical constitui um caminho que não visa à profissionalização nem à excelência na execução de instrumentos, mas tem esses parâmetros como consequências do desenvolvimento integral da criança. $O$ mais importante, neste trabalho, é a sua contribuição para a descoberta de si, para a autonomia e instrumentalização de um ser com direitos e expectativas frente ao futuro.

\section{Análise: conhecendo o desconhecido}

Para a verificação dos resultados da proposta de atendimento psicopedagógico através da educação musical foi realizado um questionário com pais, cuidadores e professores das crianças que participaram de tal atendimento. O que totalizou um número de quatro crianças que receberam atendimento por no mínimo três meses e vinte entrevistados, sendo que esses tinham conhecimento dos procedimentos adotados em aula e os pais haviam participado do primeiro atendimento junto à criança.

O questionário contava com a identificação da autora e de sua instituição de ensino, espaço para a identificação do grau de ligação do entrevistado com a criança, e duas perguntas discursivas. Para maior comodidade e possibilidade de honestidade nas respostas, o material foi entregue para ser respondido em casa, com data combinada para a devolução. Não foi solicitada identificação dos entrevistados além da já citada, mas, mesmo assim, alguns pais escreveram seus nomes e seus contatos, e um deles colocou um agradecimento pelo trabalho que estava sendo realizado com o seu filho.

Os resultados averiguados vieram ao encontro com os dados trazidos por Gainza (1988), Feres (1998), Bonora (2010) e Bertoluchi (2011) ao afirmarem que a educação musical precoce tem o potencial de desenvolver diversas particularidades do mesmo ser além dos conteúdos específicos. O que comprova as assertivas de tais autores é a analise das semelhanças de seus estudos com os dados apontados pelos pais, cuidadores e professores que acompanham as crianças com autismo que participaram da referente pesquisa.

A primeira questão abordava se o entrevistado acreditava que o atendimento de Educação Musical estava sendo benéfico à criança com diagnóstico de TEA e por 
quê. O objetivo era averiguar se os atendimentos estavam sendo positivos ou não e quais os motivos que levavam o responsável a constatar tal fato, para ter-se certeza de que os atendimentos não cumpriam um papel de entretenimento ou recreação.

Das várias respostas dadas pelos entrevistados, muitas delas foram idênticas, mesmo quando se tratava da observação realizada sobre crianças diferentes. Isso leva a autora a acreditar que o trabalho tende a estimular as mesmas áreas em sujeitos heterogêneos, pois as crianças em questão sofreram vivências diversas, não apresentavam o mesmo grau de autismo (sendo que entre eles havia diagnósticos que compreendiam autismo leve, moderado e severo), não recebiam os mesmos tipos de acompanhamento e tratamento fora da aula de música e estavam compreendidos entre as idades de três e nove anos.

Sobre a primeira questão, foram listados os motivos pelos quais os entrevistados notaram ser relevante o atendimento a crianças com a educação musical:

- melhora na socialização;

- desenvolvimento de conteúdos musicais;

- melhora na aprendizagem de se expressar;

- comunicação com mais facilidade;

- socialização em qualquer ambiente e apresentação de maior independência;

- participação nas aulas sem inibição;

- expressão de seu emocional;

- aumento da concentração;

- prazer com as aulas;

- a música tornou-se um canal de expressão e comunicação;

- melhora no desenvolvimento verbal;

- presença de maior sensibilidade;

- ambiente de alegria e harmonia;

- maior estabilidade emocional;

- maior interação social.

Já a segunda questão indagava sobre quais mudanças foram notadas após o atendimento, considerando que os entrevistados têm contato com as crianças em outros ambientes além do da aula de música, e isso lhes proporciona uma maior visão dos efeitos alcançados e de sua prolongação na vida da criança. Os fatores indicados na entrevista foram:

- melhora na atenção;

- participação nas aulas;

- boas reações com a música;

- descoberta da fala;

- aumento do contato visual;

- exploração dos sentimentos;

- melhora na interação social;

- maior autocontrole;

- melhora na comunicação; 
- melhora na motricidade;

- melhora no desenvolvimento cognitivo;

- melhora do processo lúdico;

- proporciona a criança ser mais alegre e feliz.

Todos os dados citados no questionário trazem um caráter positivo referente aos atendimentos psicopedagógicos que se utilizam das ferramentas da educação musical, sendo que foram observados avanços principalmente no desenvolvimento linguístico, emocional e interpessoal. As informações alcançadas confirmam a eficácia da metodologia proposta, pois essa foi ao encontro aos seus objetivos e assegurou benefícios de grande valia às crianças atendidas, bem como aos seus responsáveis, que se mostraram satisfeitos com os resultados.

\section{Considerações finais}

O presente trabalho propôs-se a analisar a educação musical como instrumento psicopedagógico no atendimento a crianças com Transtorno do Espectro do Autismo, observando a relação da criança com autismo e a música, e identificar os resultados de tal atendimento. Para tanto, foi utilizado o modelo de musicalização da professora Josette Feres, adaptado às necessidades das crianças que compareceram ao atendimento. O foco das aulas sempre se manteve no aluno, preocupando-se em valorizar a infância e as individualidades do sujeito, sendo que a metodologia e estrutura das aulas foram sendo adaptadas de acordo com as necessidades que se mostraram ao decorrer dos encontros.

Os resultados dos atendimentos, bem como sua repercussão em outros ambientes frequentados pelas crianças, foram constatados como positivos, sendo que sua verificação se deu pela aplicação de um questionário discursivo entregue aos pais, cuidadores e outros professores que tinham contato direto com os sujeitos que receberam o atendimento. Foram observadas melhoras cognitivas, linguísticas, de interação social, controle emocional, etc.

A criança com autismo tem um potencial muito grande dentro das aulas de música quando suas necessidades específicas são atentadas e exploradas, podendo desenvolver diversas áreas do seu ser de forma global e integrada. Tal proposta gerou benefícios necessários ao desenvolvimento e autonomia às crianças com diagnóstico de autismo, constatando a assertiva da proposta e a sugestão da ampliação do número de sujeitos investigados, bem como a ideia para uma futura investigação da manutenção dos benefícios alcançados.

A autora se sente realizada com os resultados alcançados e agradece a todos que participaram da pesquisa, por terem se mostrado atenciosos e prestativos sempre quando requisitados. Não foram medidos esforços para encontrarmos resultados que fossem satisfatórios para as crianças que receberam os atendimentos. Esperamos que tal proposta possa ser disseminada e tenha a capacidade de beneficiar tantos sujeitos quanto possível. 


\section{REFERÊNCIAS}

BERTOLUCHI, M. A. Autismo, Musicalização e Musicoterapia. CEDAP, Centro de Estudos e Desenvolvimento do Autismo e Patologias. Brasil, 2011.

BONORA, L.M.B. A intervenção psicopedagógica em casos de autismo. Artigo (PósGraduação Latu Senso em Psicopedagogia), Centro Universitário Adventista de São Paulo - UNASP - Campus 2, São Paulo, Engenheiro Coelho, 2010. Disponível em: <www.psicopedagogia.com.br>. Acesso em: 01 de dezembro de 2013.

BRASIL. Constituição (1988). Constituição da República Federativa do Brasil. Brasília, DF, Senado, 1998.

Estatuto da criança e do adolescente: Lei federal no 8069 , de 13 de julho de 1990. Rio de Janeiro: Imprensa Oficial, 2002.

Parâmetros curriculares nacionais: arte / Secretaria de Educação Fundamental. - Brasília: MEC/SEF, 1997.

RCNEI - Referencial Curricular Nacional da Educação Infantil. Brasil, 1998.

Lei de Diretrizes e Bases da Educação Nacional, n. 9.394, de 20 de dezembro de 1996. Disponível em: <http://portal.mec.gov.br>. Acessado em 01 de dezembro de 2013.

BERTAZZO, Joíse de Brum; MOSCHINI, Rosanita. Acompanhamento terapêutico escolar, o atendimento a alunos com TGD nas classes inclusivas. IX ANPED Sul, 2012.

BRITO, Teca Alencar de. Música na Educação Infantil: Propostas para a formação integral da criança. 2aㅡ. ed. São Paulo, 2003.

DSM-IV-TR - Manual diagnóstico e estatístico de transtornos mentais. Tradução de Cláudia Dornelles; 4 e.d. rev. - Porto Alegre: Artmed, 2002.

FERES, Josette S. M. Bebê - Música e Movimento: orientação para musicalização infantil. São Paulo, 1998.

GAINZA, Violeta Hemsy de. Estudos de Psicopedagogia Musical. 3. ed. São Paulo: Summus, 1988.

ILARI, Beatriz Senoi. Desenvolvimento cognitivo-musical no primeiro ano de vida. In: Em busca da mente musical: Ensaios sobre os processos cognitivos em música da percepção à produção. Beatriz Senoi llari (Org.). Curitiba: editora da UFPR, 2006. 
LOURO, Viviane. Educação Musical e deficiência: quebrando os preconceitos. São Paulo, 2004/2006. Disponível em:<www.musicaeinclusao.com.br $>$. Acessado em 12 de fevereiro de 2014.

MAROT, R. Psicosite. Disponível em: <www.psicosite.com.br>. Acessado em 12 de fevereiro de 2014.

ORGANIZAÇÃO MUNDIAL DA SAÚDE (OMS). CID-10 Classificação Estatística Internacional de Doenças e Problemas Relacionados à Saúde. Disponível em: <http:// www.datasus.gov.br>. Acessado em 12 de fevereiro de 2014.

SILVA, Ana Beatriz B.; GAIATO, Mayra B.; REVELES, Leandro Thadeu. Mundo Singular: entenda o autismo. Rio de Janeiro: Objetiva, 2012.

SOARES, Lisbeth. Atividades Musicais na Escola Especial. In: ENCONTRO ANUAL DA ASSOCIAÇÃO BRASILEIRA DE EDUCAÇÃO MUSICAL, 11, 2002, Rio Grande do Norte: ABEM, 2002. p. 211-218.

VIGÓSTSKI, Lev S. A Formação Social da Mente: O Desenvolvimento dos Processos Psicológicos Superiores. 5a edição. São Paulo: Martins Fontes, 1998.

WING, Lorna. Language, social and cognitive impairments in autism and severe mental retardation. Journal of Autism and Developmental Disorders. Número 11, páginas 31-44. 